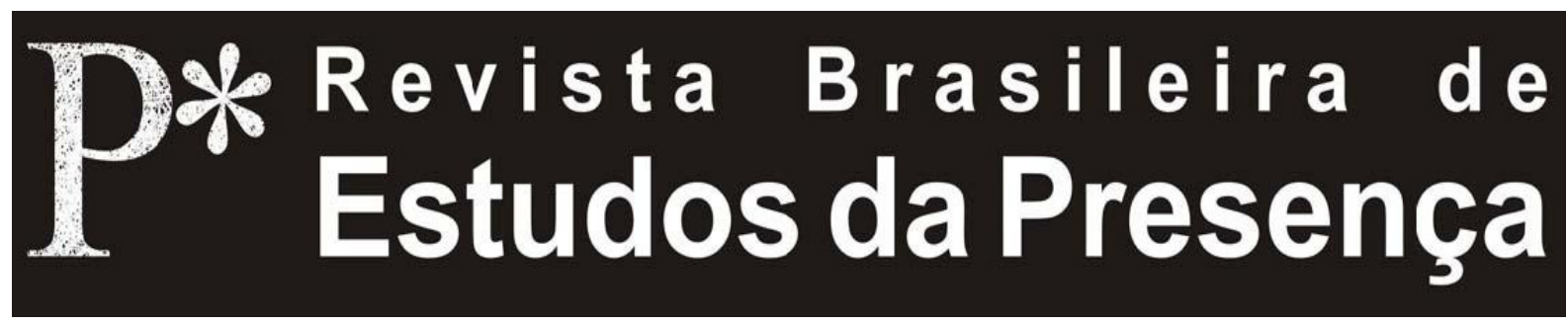

DOI - http://dx.doi.org/10.1590/2237-266030132

ISSN 2237-2660

\title{
Usina do Trabalho do Ator: reconhecimento de una identidade
}

Eliane Tejera Lisbôa

Universidade Federal de Campina Grande - UFCG, Campina Grande, PB, Brasil

RESUMO - Usina do Trabalho do Ator: reconhecimento de uma identidade - Este artigo tem como objetivo contar a trajetória da UTA - Usina do Trabalho do Ator, em seus pontos fundamentais, traçando um breve panorama de suas realizações cênicas até o momento. Buscase reconhecer, ao mesmo tempo, as características determinantes da identidade da Usina, construída e sedimentada ao longo deste percurso, tais como: a plasticidade e a musicalidade de suas realizações, a dramaturgia própria, fruto das experiências e improvisos do grupo, e a permanente e cuidadosa pesquisa atoral, apoiada essencialmente nas práticas da antropologia teatral.

Palavras-chave: Usina do Trabalho do Ator (UTA). Pesquisa Atoral. Antropologia Teatral. Plasticidade. Musicalidade.

ABSTRACT - Usina do Trabalho do Ator: the recognition of an identity - This article describes the main points of the career of the theatre group UTA - Usina do Trabalho do Ator, by making a brief overview of its scenic achievements thus far. We also seek to recognize the more important characteristics of UTA, built and set up along this career, such as the plasticity and musicality of its achievements, dramaturgy itself, a result of the group's experiments and improvisations, as well as a permanent and careful actor's research, supported mainly by theatrical anthropology practices.

Keywords: Usina do Trabalho do Ator (UTA). Actor's Research. Theatre Anthropology. Plasticity. Musicality.

RÉSUMÉ - Usina do Trabalho do Ator: reconnaissance d'une identité - Cet article a pour objectif de raconter l'histoire de l'UTA (Usine du Travail de l'Acteur), dans ses points essentiels, à travers un bref aperçu de ses réalisations scéniques jusqu'à présent. Il s'agit d'identifier, par la même occasion, les caractéristiques déterminantes de l'identité de l'UTA construite et sédimentée tout au long de ce parcours: la plasticité et la musicalité de ses réalisations; sa dramaturgie propre, résultat des expériences et des improvisations de la compagnie; et sa recherche actorale permanente et attentive qui s'appuie principalement sur les études et les pratiques de l'anthropologie théâtrale.

Mots-clés: Usina do Trabalho do Ator (UTA). Recherche Actorale. Anthropologie Théâtrale. Plasticité. Musicalité. 
O projeto de um grupo de pesquisa implica no reconhecimento conjunto dos objetivos e rumos desta pesquisa, na integração de seus membros e na constituição de um percurso que se faz no próprio fazer, a partir das religações, conhecimentos, intercâmbios nele realizados. Assim, os espetáculos produzidos pela Usina do Ator refletem também esta mesma trajetória construída a partir das oficinas e cursos das quais os integrantes do grupo participaram, sobretudo em seu(s) primeiro(s) ano(s), de suas inquietações e buscas particulares, que geraram e determinaram muitas vezes os rumos ou as facetas de suas pesquisas individuais e, finalmente, as grupais.

As primeiras experiências do Grupo, embora não tenham sido orientadas diretamente por Luis Otávio Burnier, não o deixaram de ser de alguma maneira indireta, no reconhecimento que faz a Usina do elo com as experiências daquele e dos referenciais da Antropologia Teatral junto ao grupo Lume, nas trocas diretas feitas por integrantes da Usina com atores da companhia paulista.

É evidente que, neste olhar em recuo, numa tentativa de reconstrução dos passos da Usina, desde sua origem, podemos encadeá-la numa corrente de influências vindas de Stanislawski a Barba e Burnier, passando por Grotowski, ainda que nestes 20 anos de existência outras influências tenham se feito sentir.

Pode-se dizer que, sobretudo em seu primeiro ano de vida (1992), quando o grupo ainda se encontrava vinculado à Secretaria de Cultura da Prefeitura de Porto Alegre, a influência do Lume era visível, particularmente nas configurações do clown construídas pelo grupo, de algum modo seu inicial cartão de visitas. De fato, de início a Usina concentrou sua prática em exercícios diários, num trabalho físico intenso, tomando como base o estudo das matrizes corpóreas e as pesquisas específicas sobre o clown, acompanhadas de pequenas experiências de demonstração pública dessas pesquisas, individuais ou grupais.

A partir do percurso do clown ao bufão, que dá o tom de suas performances realizadas ao longo de 1992/1993, e que determina alguns anos depois a realização de $O$ Ronco do Bugio, o trabalho se redefine, ganha nova vertente: o gru- 
po caminha para a construção de um teatro mais distante do riso, aprofundando-se em situações mais fortemente líricas ou dramáticas. O humor nunca vai estar inteiramente ausente de seus espetáculos, mas vai se distanciar sobretudo desta essencialidade clownesca, que passa a se constituir em mais um dos elementos da linguagem cênica, utilizado em distintos momentos.

Em 1994 o grupo parte para a realização de um espetáculo - Klaxon - de curta história, onde se buscava trabalhar o tema da antropofagia, tema aliás que nunca deixou de fazer parte das suas investigações, embora não expresso tão explicitamente como neste caso.

\section{Partilhando as Pesquisas}

Naquele mesmo ano, de 1994, a Usina realiza um outro espetáculo, que permanece no repertório do grupo até 1997, O Mestre Ausente. Pela repercussão positiva do trabalho, este parece definitivamente marcar um novo momento e a afirmação da Usina nos rumos da criação espetacular, muito embora tenha sido apresentado como um Espetáculo-Demonstração.

No Momento da criação de O Mestre Ausente, a Usina do Trabalho do Ator apresenta e sustenta-se em alguns elementos essenciais que são encontrados também mais diretamente nas pesquisas feitas pelo Odin, na Dinamarca, e pelo Grupo Lume, em Campinas. Estes dois grupos durante muitos anos estiveram bastante próximos através dos elos diretos de Burnier com o Odin e com o próprio Barba. A pesquisa de Burnier, no entanto, terminou por assumir um caráter específico, próprio, e com seu falecimento o Lume, através de seus integrantes, continuou a aprofundar-se nesta trajetória, sem perder totalmente os elos com o Odin. Alguns desses aspectos vão determinar uma construção específica no próprio trabalho da Usina dentro desta corrente, mas com evidente referencial extraído da Antropologia Teatral. Ao mesmo tempo já se pressente ali seu percurso particular, feito do caminho e externalização das individualidades que compõem a Usina, neste momento ainda em formação. 
A demonstração pública do trabalho, em $O$ Mestre $A u$ sente, é ao mesmo tempo explicitamente espetacular, pois na construção desta, que é uma demonstração aparentemente técnica, na definição de seus passos, verifica-se todo um sentido também de apresentação de um todo orgânico. Cada um dos momentos demonstrativos resulta num pequeno instante de elaboração cênica, e, ao longo de sua sequência, o trabalho assume cada vez mais este aspecto espetacular.

$\mathrm{Na}$ apresentação-demonstração verifica-se também um dos sentidos dessa experiência, que é permitir o aflorar das individualidades, reconhecer o ator como unidade dentro do conjunto do grupo, de modo que o grupo seja a soma destas individualidades e ao mesmo tempo um algo a mais, a partir dessa reunião de experiências que se retroalimentam. É, pois, uma demonstração técnica de técnicas, de exercícios, sua aplicação individual, os elementos utilizados por cada ator, seus pontos de partida e chegada. E numa construção didática que permite acompanhar-se simultaneamente o percurso de cada indivíduo e do grupo como um todo.

O movimento é de silêncio, de contenção e respeito, quase solenidade, neste primeiro momento do grupo, de reconhecimento do Mestre ou mestres, com apoio nos dizeres do $I$ Ching como orientador, dando a pauta de cada uma das etapas vividas. Tudo isso faz com que a Usina, na sua primeira fase, ganhe uma característica quase oriental e um pouco distante, pode-se dizer, de sua própria origem, de sua própria cultura em se pensando nos indivíduos que compõem então o grupo.

Observa-se nesse trabalho uma marca presente nos futuros espetáculos da Usina: um sentido de delicadeza, fruto de sua pesquisa, onde os atores fazem de seu corpo, nos gestos mínimos estudados, um elemento de matéria a ser manipulada. E o que essa aula espetáculo ofereceu foi justamente um espetáculo de fato, na poesia das pequenas cenas construídas, na junção acertada e melódica de movimento, fala, gesto, olhar e o encontro com o outro.

O espetáculo traz em si também uma antevisão do que serão na sequência os próximos espetáculos do grupo, ou pelo menos os seus espetáculos de sala fechada, com a exploração 
ampla do espaço quase vazio, o corpo do ator como referência máxima e mínimos objetos para construir a cena.

Com O Mestre Ausente prenuncia-se a intrepidez do grupo que, após ver-se na impossibilidade de contar com o mestre desejado, por seu prematuro desaparecimento, encontra um rumo de inesperadas e infinitas riquezas, ao assumir a ideia de que há um mestre em cada um dos elementos explorados e em cada um de nós.

\section{Novos Rumos}

A Usina a partir de então se reconfigura, restando, pois, apenas dois remanescentes da formação original, Celina Alcântara e Gilberto Icle, que tinham vivido e participado desde o início da intensa pesquisa corporal realizada inicialmente a seis, depois a quatro pessoas, como apresentado no espetáculo-demonstração. Também se definem novos rumos com a chegada de outros integrantes, como Leonor Melo e, em particular, Ciça Reckziegel, que a partir de $O$ Ronco do Bugio vai estar presente em todos os espetáculos produzidos (à exceção do solo de Icle), inclusive assumindo uma direção, além de muitos outros atores que passam pela Usina ou são convidados especialmente para uma ou outra montagem.

Desde o início da história da Usina, ao que parece mais por necessidade do grupo do que exatamente por uma opção pessoal, Gilberto Icle assume o papel de diretor, numa prática que vai se estender de Klaxon, passando pelo EspetáculoDemonstração, e que tem continuidade nos demais espetáculos realizados: O Marinheiro da Baviera, O Ronco do Bugio, Mundéu, A Mulher que Comeu o Mundo e 5 Tempos para a Morte. Única exceção, Nos meses da Corticeira Florir, dirigido por Ciça Reckziegel. Naturalmente, o olhar da direção termina definindo uma linha de trabalho, ou no mínimo pontuando algumas marcas próprias, de espetáculo para espetáculo, mas, no caso da Usina um aspecto importante a ressaltar, na sequência de espetáculos criados, é que cada um deles reflete de algum modo as pesquisas fundamentais desenvolvidas pelo grupo naquele momento. 
O Ronco do Bugio abre uma nova frente na linha de trabalho da Usina, e dá início a uma abordagem que busca as raízes próprias da cultura do Rio Grande do Sul. O espetáculo nasce como resultado de uma oficina sobre o bufão ministrada pelo grupo, onde se explorava a figura do bugio, e que contou com a participação de um grande número de atores, alguns dos quais, como vimos, passam a integrar a companhia.

$\mathrm{Na}$ construção dos personagens agora, mais do que preocupação com as matrizes corpóreas, acentua-se o jogo bufonesco, em gestos livres, onde cada um dos atores constrói seu próprio bugio. Explora-se uma gestualidade circense também nas inúmeras acrobacias, nos saltos e nas construções piramidais de apoio aos atores.

Primeiro espetáculo de rua da Companhia, é visível a pouca experiência do grupo nesta modalidade, de exigências bastante distintas do teatro no espaço fechado. Mas ela se revela o momento de maior ousadia espacial da Usina, que, deste ponto de vista, em suas próximas cenas de rua vai delimitar o espaço cênico, restringindo-se a uma apresentação formal na rua.

Como espetáculo de rua, O Ronco do Bugio busca atender a todas as exigências desta, no sentido do exagero, do colorido, de musicalidade e amplitude gestual. Os atores transformam-se em bugios vestindo roupas coloridas com muitos enchimentos por baixo das mesmas, salientando bundas e corcundas. As maquiagens, embora distintas e estilizadas, são todas fortes buscando construir a figura do macaco. São introduzidos inúmeros instrumentos musicais em cena, entre eles três acordeões, tambores, caixas e castanholas, que vão permitir chamar sempre de modo mais efetivo a atenção do público, além do uso da perna de pau e do pau de fita, mais um elemento da cultural local, e que dão um tom circense ao construído.

O Ronco do Bugio é, assim, momento de passagem da Usina, de um trabalho mais intimista, de espaço fechado, para o trabalho aberto, na rua, expansivo e abrangente. Além de momento importante de redefinição do elenco, o trabalho é também de uma linha de construção de espetáculo, onde as propostas do teatro antropológico e suas técnicas passam a 
ser aplicadas ao universo da cultura original do grupo, dandolhe características mais precisas e definindo o seu caminho específico de pesquisa e criação. Os posteriores espetáculos da Usina vão refletir e afirmar esta mudança de rumos.

Nova experiência para a dupla de atores que seguia uma trajetória conjunta há anos, novo momento e possibilidade de aprendizado para os atores que a ela vêm se juntar. Definição também de inserção definitiva de novos elementos na prática do grupo, a partir da oficina e do espetáculo. A musicalidade e a plasticidade crescem e ganham espaço nas novas propostas espetaculares a partir daí, pois o grupo passa a contar em permanência com a participação de profissionais de outras áreas, como o músico e compositor Flávio Oliveira, o artista plástico, cenógrafo, figurinista e aderecista Chico Machado e Marlene Goidanich, na pesquisa vocal.

Com essas novas parcerias os espetáculos da Usina ganham também uma força sonora e visual que configuram o novo perfil de suas encenações, algumas vezes alcançando mesmo o caráter bastante especial de uma cena performática, tal a força, sobretudo visual, que a constitui. Ao mesmo tempo, a presença musical, com os atores assumindo os instrumentos em cena e muitas vezes também dançando, aliada à plasticidade dos figurinos, máscaras e adereços, implicam numa pesquisa de linguagem que amplia o trabalho atoral, mesmo com o risco de serem necessárias idas e vindas para que não se perca o rumo essencial da pesquisa do ator, de sua fisicalidade essencial em cena que, ao que parece, ainda se mantém como base do processo de criação da Usina.

\section{Um Hiato Cênico}

O Marinheiro da Baviera, diretamente vinculado a essa essencialidade - quase um hiato na trajetória do grupo -, é realização exclusiva de Gilberto Icle como resultado de sua própria pesquisa corporal. Ao mesmo tempo, é preciso reconhecer que um certo lirismo essencial, de evidente força em O Marinheiro da Baviera, já se encontra presente também nas pequenas performances apresentadas em O Mestre Ausente, ainda em 1994. 
Mas, O Marinheiro da Baviera é um solo, feito de silêncio, de olhares e gestos; de vozes, cantos, entonações e entoações; de um movimento e desenho de mínimas feituras e múltiplas leituras, com um ator que se mostra e se refaz a cada momento em muitos personagens, nas vozes e nos pequenos gestos. O marinheiro recorda o vivido e o não vivido, constrói uma história que nos chega em fragmentos, e que construímos apesar dele, e com ele, com o que nos diz e com o que cala. E que se faz também contraditória, fragmentada, incompleta, imaginária mais do que tudo.

A precisão do gesto de Gilberto Icle, o seu movimento e desenho cênico, definem o marco da cena, onde o espectador caminha com olhos e ouvidos atentos. O espetáculo é intimista, estando o palco praticamente vazio, num pequeno espaço determinado por um mínimo de objetos, com época e local de origem do personagem identificados pelo figurino, e um ator que se desdobra em muitos, desdobrando também o tempo e o espaço.

Estreado em 1996, o espetáculo é uma demonstração precisa do processo de trabalho inicial da Usina, e talvez o seu modelo mais significativo do ponto de vista do uso das matrizes corpóreas em cena, por sua precisão, economia e desenho gestual. Pesquisa de ator, pesquisa de linguagem, $O$ Marinheiro é quase um espetáculo demonstração também, não fosse a orgânica expressão do ator nos gestos codificados que constroem com clareza a narrativa.

O material temático é uma somatória de buscas de história pessoal, cruzada com textos de Erico Veríssimo, Fernando Pessoa e Rainer Maria Rilke, além do uso de composições de Johannes Brahms. Durante a apresentação o público fica em conexão direta e permanente com o ator que encadeia os momentos com pequenas canções, extratos de texto, cenas e silêncios. $O$ espetáculo é marcado pela inteligência de sua construção na identificação do que é essencial nesta escrita visual-sonora poética.

Gilberto Icle, com O Marinheiro da Baviera, traz para a cena o resultado de sua pesquisa atoral dos anos anteriores, e volta aqui a incursionar como (seu próprio) diretor. Isto faz com 
que possa aliar sua pesquisa atoral a um olhar cênico, que lhe permite construir as imagens que desenha e, ao mesmo tempo, aproveitar ao máximo os recursos das matrizes corpóreas cuja construção explorava ao longo desses anos.

As partituras construídas pelo ator, pequenas faíscas dos instantes vividos pelo personagem, são suficientes para que se possa construir toda uma vida, em sua fragilidade, fracassos e aspirações. Gilberto Icle domina a cena, o espaço e o contato com o público através de um olhar permanente e inflexivo.

Enquanto o uso do poema de Fernando Pessoa, O Marinheiro, dá ao público a licença poética de entender que nada ali se passou de fato como real, que tudo foi um sonho de Carl, ou talvez mesmo do ator sobre ele, ou sabe-se lá se da plateia sobre o ator. É infinito o abismo, o jogo de espelhos, mas as imagens e sons apresentados são reais, e impregnam para sempre a memória do público.

\section{Em Busca de uma Identidade}

Com o próximo espetáculo da Usina, o que se observa é a intensa procura de uma identidade própria, o que a leva muitas vezes a querer beber em todas as fontes como caminho para encontrar o seu próprio lugar. Assim é o caso de Mundéu, onde, nas palavras do próprio Icle no programa da peça, a presença

[...] da dança indiana, do Chaolin do Norte, do ballet clássico, da dança flamenca, referências plásticas indígenas, do oriente, do Nordeste e do Sul do Brasil, ritmos nordestinos, marcações indígenas, a forma do ritual afro-brasileiro é um modo de questionar a própria identidade e reeditar a metáfora antropofágica (Mundéu..., 1998, programa).

Sem falas, o espetáculo apoia-se, para a compreensão de sua narrativa, nos versos das canções e na movimentação e coreografia dos atores. Estas se mantêm no limite da ilustração da história, do acontecimento, numa aparente tentativa de construir na cena um nível de representação característico do teatro oriental. O grupo evidentemente não pretende, nem o poderia, com tão poucos anos de trabalho, reproduzir estas práticas orientais de teatro/dança. O que temos aqui é de algum 
modo um exercício de aproximação, uma demonstração de aspectos característicos desse teatro e o uso e aproveitamento de alguns de seus elementos num trabalho em que a Usina caminha em busca de sua própria forma expressiva.

Não se trata mais simplesmente de definição de matrizes corpóreas e de construção de momentos cênicos a partir destas, e sim de uma dança que se aproveita de elementos das danças estudadas e as transporta para um universo ocidental onde a gestualidade construída às vezes ilustra momentos definidos da narrativa, gerando em outros momentos um certo sentido de carnavalização.

Do ponto de vista musical, dá-se continuidade à parceria iniciada em $O$ Ronco do Bugio, aproveitando-se ainda mais a particular linha composicional de Flávio Oliveira, em função dos distintos climas gerados pelo espetáculo. Em Mundéu, a música assume lugar fundamental, de guia e força motriz do trabalho, já que o espetáculo é sem falas, e o trabalho atoral é, na sua essência, também um trabalho de dança. Compositor de larga experiência e reconhecimento nacional, Flávio Oliveira aproveita e ilumina cada uma das nuances da cena, e de seus muitos universos, pois Mundéu é também uma dança entre o universo da magia, do mundo fantástico e da realidade, do dia e da noite, das forças do bem e do mal. O trabalho musical alia-se ao jogo de iluminação permitindo uma permanente mudança de climas, onde tudo está pontuado basicamente pela força dos tambores que determinam entradas e saídas dos personagens e acentuam sua movimentação. Além disso, pequenos instrumentos, como o uso da flauta, de castanholas ou dos guizos presos ao corpo dos bailarinos, ajudam a colorir a sonoridade da cena.

A canção também mantém seu papel já presente em $O$ Ronco do Bugio, de narradora do espetáculo. São pequenos versos, simples, de estrutura clara, cantados pelo grupo ao correr das cenas para que se conheça a fábula básica construída, na verdade uma mescla de muitos elementos. Os atabaques marcam e pontuam a movimentação, e contribuem também com outros momentos de sonoridades não meramente ilustrativas, criando climas, sensações e nos colocando nos universos fantásticos dos personagens lendários. 
Além da musicalidade que pontua cada um dos momentos do trabalho, é através de sua plasticidade que ele se configura como significativo. $\mathrm{O}$ grupo demonstra seu nível de exigência profissional ao tomar Chico Machado como parceiro para a realização dos figurinos e adereços. Toda a concepção das figuras fantásticas e do figurino do casal de humanos é um trabalho conjunto de estilização e narração. A exuberância de suas cores, bastante próxima dos elementos do teatro oriental, encontra também referências no nosso carnaval ou nas figuras das brincadeiras festivas nacionais.

Mundéu é realmente um mundo de coisas, como o significado da própria palavra expressa. Quase se percebe aí o desejo do grupo de aplicar todos os conhecimentos adquiridos ao longo dos anos, de experimentar em cena todas as novidades da gestualidade encontrada em suas pesquisas e vivências. Muitas destas experimentações terminam sendo uma construção para si, onde a Usina vive o prazer de mostrar ao público alguns aspectos das pesquisas realizadas, tal como acontece em O Mestre Ausente e vai acontecer também em A Mulher que Comeu o Mundo. O público, não necessariamente conhecedor dos códigos das pesquisas exploradas no trabalho, identificase com a cena a partir de outras leituras que faz, dos aspectos próprios a cada um de seus momentos, e pela exuberância de sons, imagens e gestos. Há um evidente sentido antropofágico de aproveitamento de materiais e sua inserção em universos que lhe são alheios, e neste sentido Mundéu coloca-se como trabalho experimental, correndo todos os riscos daí resultantes.

No entanto, fazendo uso de elementos colhidos em universos tão distintos na cena, Mundéu oferece ao mesmo tempo uma narrativa simples, definida não apenas por seus cantos, mas pela gestualidade de ilustração precisa em muitos momentos, às vezes próxima do óbvio, de tom quase circense, em outros determinada por gestos simples, de escolha bastante feliz.

O grupo, que num movimento pendular parece passar a cada novo espetáculo da grande visibilidade da rua ao palco fechado, em Mundéu coloca-se o desafio de experimentar ambas as possibilidades, com apresentações tanto na rua como 
no palco. Mas a relação com a rua está mais contida, como se domada pela decisão de nela construir um espaço similar ao dos rituais afro-brasileiros, com os músicos presentes em cena, o que determina uma relação de semifrontalidade.

Esta ambiguidade, expressa num espetáculo que se propõe passível de apresentação tanto na rua como no palco, como acontece depois com A Mulher que Comeu o Mundo, na verdade se coloca no campo de pesquisa da Usina como uma ambiguidade de caminhos a seguir. A pesquisa, voltada para a ampliação da fisicalidade atoral, de prática de exercícios e definição de uma técnica, possibilitando uma construção meticulosa, de mínimos detalhes, não alcança na rua o seu efeito maior de precisão. Este se dilui, em meio à movimentação exacerbada e visualmente forte que a rua exige, ou que pelo menos os trabalhos construídos pelo grupo para estes espaços oferecem.

Mundéu, de alguma maneira, parece refletir a ansiedade ou o desejo de abarcar todas as culturas, de sentir-se cidadão do mundo, de identificar os pontos de encontro entre as nossas tradições e as culturas de povos distantes, de mesclar nosso imaginário com o alheio, de pesquisar uma identidade, mas encontrá-lo multifacetada em muitas outras identidades. Esta busca, de algum modo, em certos momentos afasta o público de uma compreensão imediata do universo apresentado, neste jogo de códigos e referências que nem sempre se domina. Isto dá também uma universalidade ao espetáculo, mas Mundéu parece estar a meio caminho, como trabalho realmente de passagem do grupo para novas experimentações.

Talvez mesmo por isso, após dois espetáculos de rua, distintos e de algum modo excessivamente abertos na sua proposta corporal e temática, o retorno para o espaço do palco possa quase ser visto como um passo natural do grupo, numa aparente tentativa de recuperar um pouco da essencialidade perdida ou abafada nos trabalhos anteriores.

Enquanto, em sua nova configuração, com todos os integrantes já tendo vivenciado um período intenso de trabalho em conjunto e integrados às práticas de pesquisa atoral, a Usina pode se permitir um novo salto agora, aproveitando as experiências e pesquisas realizadas. 


\section{Novo Momento Particular}

Nos Meses da Corticeira Florir, por vários aspectos, vai se revelar como um momento bastante específico dentro da trajetória da Usina. Como marco importante, o grupo abre-se a um novo olhar na direção, com Ciça Reckziegel ocupando a função, o que gera um espetáculo diferenciado, mesmo que ainda apoiado na linha fundamental de pesquisa e criação a partir da fisicalidade do ator. Talvez por isso mesmo, identifica-se uma linguagem também diferenciada na construção do trabalho.

O espetáculo estabelece uma maior intimidade na relação com o público, inserindo-o diretamente no espaço da cena, como se fizesse parte dela, com o convite para que ingresse na sala da casa de Anita, aonde vai fazê-lo também experimentar a cachaça que vende a índia Anaí. Um mínimo de objetos estão presentes para definir o essencial do lugar onde nos encontramos: a casa de uma fiandeira. Uma roca ocupa o centro da cena. A lã, em cestos, pronta para ser fiada, em outros cestos, panos. Pelegos e um banquinho, onde se senta Ana. À chegada da terceira personagem, Anaí, o público inclusive vai receber das mãos de Ana uma prova da cachaça que a andarilha está vendendo.

O espetáculo é, assim, uma sequência de narrativas, particularmente da lenda Anaí, de Barbosa Lessa, que se entremesclam à situação presente, em que três mulheres e um homem convivem num jogo de descobertas mútuas, ao mesmo tempo desenhando as relações tradicionais de papéis sociais e de gênero, que em momentos mágicos serão rompidos.

O espetáculo tem uma estrutura sintética determinada por um claro conjunto de elementos, gerando uma narrativa concisa e acessível de imediato ao público, e equilibra-se numa diversidade de atmosferas, passando do humor à luta e a momentos líricos, poéticos, que se constroem pelo jogo das atrizes e pela musicalidade que o apoia. Ao mesmo tempo, na sua atuação, atrizes e ator traçam este mesmo desenho em gestos precisos, onde a construção de matrizes corpóreas coloca-se como indício, mal se adivinhando na precisão e beleza dos movimentos, gestos e danças envolventes e claros. 
Movimento e gesto das atrizes e do ator, com poucas falas, constroem os ambientes, representam situações, numa proposta de simplicidade e essencialidade e nos transportam para outros momentos, tempos e espaços.

A construção musical do trabalho pauta-se pela sensibilidade no uso dos materiais sonoros, todos eles vinculados ao universo cênico proposto. A roca serve como motivo de fundo musical enquanto as mulheres conversam. Ao aproximar-se a guerra peneiras e pilão vão ser introduzidos cumprindo o mesmo papel, dando ritmo e intensidade à narrativa. Este jogo reforça-se com a introdução de cantos e danças de rituais afros, onde se revela o trabalho vocal apurado das atrizes, e que vão aumentando de intensidade até atingir seu auge em momentos cruciais da narrativa.

O ritmo envolvente dos batuques e das danças são também motivos de permanente envolvimento de quem os assiste, e a história, que se desenvolve num crescente até transformarse num turbilhão de guerra e sedução, leva consigo o público para o campo de batalha e para os jogos de amor.

Há uma inteligência e aproveitamento cênico de todos os elementos utilizados, como o das saias das atrizes, que são usadas de diferentes modos, transformando-se, ganhando novas cores, compondo espaços e servindo para muitos fins, desde a ideia da noite, a cobertura ou tenda do pajé, a saia da mãe de santo até a mortalha do soldado. As transformações dessas saias são um prenúncio da surpreendente saia de $A M u$ lher que Comeu o Mundo, que é um espetáculo em si mesma.

Assim como os personagens e figurinos sofrem transformações, em Nos Meses da Corticeira a cena como um todo é reconfigurada. Desaparecem os objetos de cena e, no vazio do palco, espalham-se flores, conformando-se de imediato um espaço ritualístico, com atores e plateia colocados num momento de extrema concentração, onde o ritmo é crescente e envolvente.

Revela-se também no espetáculo a inteligência de sua construção na interação de cada um de seus elementos, e da direção com o conjunto de atores, onde se adivinham as possibilidades que as muitas propostas nas improvisações 
podem ter gerado e o seu aproveitamento na escolha precisa e funcional para cada um dos momentos cênicos.

Nos meses da Corticeira Florir parece ser um salto no sentido de compreensão e apreensão dos elementos pesquisados ao longo de todos estes anos pela Usina, aqui deglutidos, transformados numa construção própria, onde a linguagem do grupo se entrelaça com suas próprias tradições, com sua cultura, e abre-se para a relação com o público, revelando uma construção cênica de jogo amadurecido e leve.

O trabalho retoma as parcerias com Flávio Oliveira na composição musical, Chico Machado na cenografia, figurinos e adereços, e Marlene Goidanich na preparação vocal, um trio de profissionais competentes e sensíveis, já encontrados em Mundéu. Todas estas parcerias, constantes ao longo dos anos, certamente geram um espírito de grupo e integração à proposta realizada que explicam a unidade sentida no seu todo.

Em Nos meses da Corticeira Florir a Usina parece ter encontrado uma identidade própria, sem tradicionalismos estreitos, mas fazendo uso dos elementos de sua própria cultura para escrever um espetáculo com tons universais. O drama construído é o de todos, a forma é a própria de quem nos conta, alimentada pelas pesquisas da antropologia teatral, e a compreensão se faz acessível e imediata por qualquer um que a assista. O grupo está de modo claro fazendo uso da pesquisa de outras tradições, para alimentar a sua, e a nossa, compreensão, de nossas próprias tradições.

\section{Reconhecimento}

Depois desse período de contínuas realizações, os integrantes da Usina partem, por um momento, para desenvolver outros projetos. Por alguns anos a Usina deixa de produzir espetáculos, refletindo talvez incertezas sobre o futuro da companhia e como fruto também dos compromissos pessoais de seus integrantes, muitos deles concluindo ou iniciando atividades acadêmicas. Felizmente este momento foi um positivo gerador de novo impulso, na medida em que se afirmam os novos lugares ocupados por cada um, dentro e fora do grupo. $\mathrm{O}$ fortalecimento teórico certamente é uma resultante direta 
disso e as novas práticas vieram a sedimentar-se por um rico material, não só de leituras, mas de trocas com outros parceiros, professores, colegas, estudantes e pesquisadores de um modo geral.

Assim nasce A Mulher que Comeu o Mundo, como um estudo do grupo sobre o uso das máscaras e baseado numa fábula bastante simples, mas que marca para sempre o cenário do teatro brasileiro com a imensa saia concebida por Chico Machado. Sem qualquer dúvida, a força do espetáculo apoia-se na enorme visualidade e beleza dos figurinos, que remetem mais uma vez ao oriente, de onde se procura extrair também a movimentação e particularmente o caminhar dos atores. Mais uma vez também encontramos aqui a narrativa feita através das canções, e toda a cena é praticamente uma grande alegoria, na imagem desta devoradora de tudo e todos, onde nada mais resta a não ser ela mesma em sua profunda solidão.

A Mulher que comeu o Mundo marca também o lugar que a Usina passa a ocupar como grupo reconhecido nacionalmente, viajando para diversos lugares e ganhando prêmios em muitos eventos e festivais. Marca de um retorno à cena num outro plano, em que o caráter profissional do grupo se consolida, ao que tudo indica, de modo definitivo. Também aqui o grupo ousa experimentar o espaço da cena fechada em paralelo com o da rua, mas, como já observamos, mantendo-se numa disposição fixa, neste caso em arena, com o público se colocando para assistir a um espetáculo como se estivesse no palco. Mas, talvez, neste caso, nem pudesse ser diferente com um material cênico de tal porte, como a imensa saia que, por si só, constitui uma clara invasão e ruptura com o cotidiano da rua.

Em 2010, o grupo vai retornar ao espaço da intimidade, com 5 Tempos para a Morte, trabalho que, de algum modo, também é uma retomada de todas as experiências anteriores, com um elenco amadurecido e capaz de contribuir para os processos de criação resultantes de improvisos, e sem abandonar as pesquisas atorais fruto destes longos 20 anos de trocas e experimentações. Interessante observar que, ao falar da morte, o grupo se propõe a falar da vida, refletindo 
sua própria trajetória, onde a Usina está sempre renascendo e, neste momento mais do que nunca, abrindo seus processos criativos e realizações para as trocas de experiências, e as produções reflexivas, acadêmicas ou não, de seus integrantes. Momento de falar de sua história, deste grupo que tem hoje uma identidade própria, mas que não se acomoda nela, que incessantemente se reinventa, e momento de falar de si, das histórias pessoais, de cada um destes que o integra e redefine, em constância, a identidade da Usina no seu próprio redefinirse enquanto ser e artista criador.

\section{Dominando Espaços}

Neste sentido, pode-se mesmo afirmar que a Usina mantém-se fiel a um de seus princípios básicos: é do material elaborado e trazido por cada um dos atores, em suas pesquisas individuais, que se constitui a matéria elementar a ser trabalhada na criação dos espetáculos. Assim, a realização de qualquer espetáculo é sempre uma somatória de olhares e contribuições individuais, e o que o grupo fez foi ampliar esta perspectiva agregando às suas realizações um número mais amplo de novos e distintos olhares, o que, se o abalou, ao mesmo tempo enriqueceu os processos vividos até então. Além da pesquisa atoral precisa, centrada na fisicalidade do ator, outro aspecto fundante da prática espetacular da Usina é determinado por sua relação com o público, pela escolha da espacialidade instaurada na realização de cada um de seus espetáculos.

Já em $O$ Mestre Ausente a relação com o público revela o caráter de intimidade que vai caracterizar, de modo geral, os espetáculos em espaço fechado do grupo. Uma arena, ou semiarena no caso, o despojamento - um espaço vazio, o chão como base de contato entre público e atores. Um espaço onde a fronteira entre um e outro é mínima, apenas a disposição final da frontalidade neste pequeno ambiente, que era afinal também o ambiente de trabalho do próprio grupo, estando por isto carregado justamente desta energia concentrada das horas de vivência e prática grupal e individual. Neste espetáculo- 
demonstração, só se aceita um número reduzido de pessoas a cada uma das apresentações, não só pela própria exiguidade do espaço, mas, sobretudo, pela proposta que se quer desenvolver, de apresentar, de modo íntimo, no próprio ambiente onde se pesquisa, alguns dos resultados alcançados.

A demonstração é uma generosa oferta ao público do que se conseguiu construir ao longo dos anos, num trabalho paciente e exaustivo, de (des)construção deste corpo que se oferece como objeto a ser manipulado e desenhado em função do que se quer dizer, e que se oferece também como mensageiro do próprio dizer, gerador das falas que ele próprio constrói e expressa. Nesse espaço íntimo construído, o grupo apresenta-se em diálogo com o público, que se torna testemunha de seus passos diários, de suas conquistas, das descobertas feitas, dos saltos perceptivos, de compreensão, de trabalho e de construção do real, de um novo real.

As experiências de rua, numa dimensão toda outra, não deixam de trazer ainda esta mesma concepção, no sentido da aproximação, do ir até onde o público está, mas levando a ele o teatro, procurando o diálogo, o encontro. Assim, os bugios passeiam pela cidade, atravessam ruas e praças, conduzem o público e vão ao seu encontro, envolvem-no, dançam em torno dele, é uma loucura de alegria e ruídos como um verdadeiro bando de macacos soltos na cidade.

O percurso da Usina vai nessas duas vertentes, como uma caixa de fole que se abre e se fecha, do barulho da rua, do colorido exacerbado, intenso, dos figurinos grotescos, lúdicos, ao espaço interno, íntimo, do pequeno número de espectadores, na sala de trabalho, no ambiente fechado da criação, um público cúmplice das próprias etapas do percurso. Assim, é um abrir e fechar, do Mestre Ausente ao Ronco do Bugio, do Marinheiro da Baviera ao Mundéu, de Nos Meses da Corticeira Florir à Mulher que comeu o Mundo e, desta, a 5 Tempos para a Morte. Como ondas do mar, passa-se da rua, do espaço aberto, da agitação e da alegria, do gesto amplo e da fala solta, para o íntimo, o recolhido, a minúcia do gesto contido e sua força expressiva, a possibilidade da cumplicidade no silêncio e no jogo de olhares, no toque e na proximidade. 
Mas há sempre cumplicidade, sempre intimidade, sempre jogo dirigido para o público imediato, seja na rua, seja no espaço fechado. Tudo é uma questão de redimensionamento, de ampliação e contenção, mas a proposta é sempre a de chegar ao público, de reconhecer sua presença, de falar com e para ele. De trazê-lo para o jogo, como copartícipe.

\section{Parâmetros de uma Identidade}

Pode-se reconhecer hoje na Usina algumas marcas que a identificam, como frutos desta história construída, sobretudo, com pertinácia. Do ponto de vista de sua estética podemos identificar alguns parâmetros definidores, entre eles esta procura constante por uma linguagem antropofágica, que já se anunciava em Klaxon, como uma brincadeira aparente. Ela vai se desdobrar em permanente investigação sobre universos tão distintos como o kathakali indiano, todas as pesquisas antropológicas vinculadas ao universo oriental, e que são trazidas, absorvidas e transformadas, em montagens que atravessam a história e as expressões culturais de nosso país e, particularmente, do Rio Grande do Sul. Do bugio ao chimango, às lendas da Salamanca e de Anaí, o mundéu da Usina é amplo e enraizado em seu próprio chão.

O trabalho de atuação, que também encontra apoio em todas as pesquisas essenciais da antropologia teatral e seus desdobramentos nas experiências do Lume, se amplia no grupo nas trajetórias de cada um dos atores, a partir de suas próprias formações e buscas individuais em diferentes correntes e práticas atorais. $\mathrm{O}$ cruzamento disso revela hoje um grupo com uma sólida formação, em que a dramaturgia dos atores é elemento essencial para a construção de cada um de seus espetáculos.

A dramaturgia construída para cada trabalho, fruto de experiências e improvisos, já traz de antemão o potencial existente de cada um dos atores que pode se colocar também como dramaturgo da cena como um todo, com suas contribuições. Corpos disponíveis, prontos para o jogo, e abertos à experimentação neste cruzamento constante de culturas em que se projeta a Usina. Atores capazes de cantar, tocar, dançar, com 
domínio do espaço e geradores de energia cênica permanente. Se o número de integrantes foi variando ao longo dos anos, um núcleo central e ampliado permanece, que dá garantia à permanência também da própria poética que o grupo vem construindo. Permanência, portanto, de sentido do percurso que se reelabora a cada montagem, mas que tem raízes sólidas.

Outra das marcas do grupo é, assim, esta dramaturgia que surge da cena, do processo, e que vai caminhando, investigando narrativas, trabalhando com o texto que nasce das contribuições dos atores, de suas criações ou descobertas e paixões nas palavras de outros, poetas da letra ou da cena também. E a cena vai se construindo neste mosaico, que já nas demonstrações de $O$ Mestre Ausente se anunciava, num jogo de substituição de bastões por objetos, de cruzar de falas e gestos, de desenhos de movimentos a que se somavam frases, textos, poemas.

Mas esta dramaturgia da Usina também tem um sentido claro de pesquisa que passa pelos rumos da antropofagia, da antropologia teatral e da etnocenologia. Uma investigação se faz também aí, nesta procura das raízes temáticas, de uma história cultural feita de lendas, de mitos, de fatos históricos e inclusive de comportamentos humanos espetaculares.

Deste transitar da Usina por sua pesquisa dramatúrgica, os resultados mais claros e determinantes de sua poética, evidenciados em sua prática espetacular, se colocam na construção das imagens, de uma visualidade quase imponente. Figurinos e música, aliados ao canto e ao gestual, combinamse para construir uma permanente poesia múltipla, sonora e visual, colorida e intensa, onde a hiperbólica saia da mulher que comeu o mundo é o seu exemplo mais paradigmático.

Naturalmente, são figuras emblemáticas da Usina o artista plástico Chico Machado e o compositor Flávio Oliveira, mas entendemos que estas parcerias se consolidam e se afirmam justamente porque são fruto de um sentido que perpassa o grupo desde seus primeiros momentos. Músico e artista plástico vêm ao encontro das necessidades do grupo e contribuem, com suas criações, para fortalecer este sentido original. 
As pesquisas com as pinturas das máscaras faciais, as roupas de referências orientais, até mesmo na reconstituição de lendas tão nossas, dão a Chico Machado o caminho para a exploração de todo seu potencial criador. Ao ponto de a cena, normalmente nua, despida de todo e qualquer cenário, ser preenchida pela presença quase invasiva destes figurinos que tomam conta do espaço, e atraem inflexivelmente os olhares. A cena da Usina é também uma cena plástica, essencialmente uma pintura de muitas cores e combinações plásticas.

Quase ao inverso disso, os versos e a música de Flávio Oliveira se colocam como uma contribuição determinante para a apresentação das narrativas. Revela-se neles o sentido da trama, através de melodias aparentemente simples, e com os atores responsáveis pela produção desta musicalidade em cena, tocando diferentes instrumentos, fazendo uso de materiais distintos a cada encenação, preenchendo o espaço cênico de uma sonoridade que corresponde exatamente ao tema de que ela trata.

Assim, mais do que uma apresentação onde encontramos uma fábula explicitada no diálogo entre os personagens, a narrativa da Usina nos leva por outros caminhos, onde são as imagens, os gestos e os sons que nos contam o acontecido. São as danças e as imagens que conduzem o público e constroem os muitos espaços da cena, quase sempre abstratos: espaços do imaginário, do fantástico, de amores e lutas, de ambição e memória. Espetáculo sonoro e visual, o trabalho da Usina não dispensa, no entanto, e continua tendo no seu cerne a figura do ator, com sua gestualidade e precisão, fruto das pesquisas iniciais e permanentes sobre a construção das partituras.

Ao longo dos anos definem-se ou afirmam-se os papéis, com Gilberto Icle fixando-se como diretor, ainda que não se excluam outras possibilidades, como a vivência de Ciça na direção em Nos meses da Corticeira Florir. Torna-se significativo, dentro disso, o fato de que, na última produção da Usina, Icle tenha ficado de fora do palco pela primeira vez, assumindo exclusivamente o papel da direção. Mesmo que isso aconteça por um mero acaso ou contingência, podemos inferir que o olhar deste diretor, gestado na própria história da Usina, 
vai ganhar a partir daqui um amadurecimento e definição a que até então não se tinha permitido.

A Usina, que por um tempo pareceu vacilar em sua existência, provavelmente em razão das inserções de seus integrantes no mundo acadêmico, retoma seu lugar e de maneira mais definida, à medida que este movimento começa a dar seus frutos. Hoje, o grupo é também marco reflexivo nos trabalhos paralelos que cada um desses profissionais da cena desenvolve em pesquisas e estudos, como professor ou pesquisador. A Usina, portanto, se desdobra em experiências múltiplas fora do quadro do próprio grupo, mas refletindo e partilhando as descobertas que se fazem em seu seio a um universo teatral mais amplo, compreendendo outros criadores e estudiosos desta arte.

Ao se fazer uma análise desses 20 anos de história da Usina verifica-se que, de fato, ela se permitiu sempre mudanças inesperadas dentro de uma linha de trabalho, de certo modo, rígida. E são estas mudanças, com a integração de novos atores ao grupo, a introdução de novos elementos e materiais de cena, a colaboração de outros profissionais de áreas distintas e a experimentação de novas direções no processo criativo que determinam a construção desse repertório diversificado, dessa série de espetáculos distintos. Ao mesmo tempo, elas são as responsáveis pela elaboração de matéria fundamental para a construção e o reconhecimento de sua própria identidade. 


\section{Referências}

LISBÔA, Eliane. Diálogo Coletivo com Integrantes do Grupo. Transcrições de Gravações. 2002. Comunicação Verbal.

MUNDÉU o Segredo da Noite. Programa de Apresentação. Produção da Usina do Trabalho do Ator. Porto Alegre, 1998.

O MESTRE Ausente. Registro de Arquivo. Apresentação teatral produzida pela Usina do Trabalho do Ator. Porto Alegre, 1995. 1 VHS.

O RONCO do Bugio. Registro de Arquivo. Apresentação teatral produzida pela Usina do Trabalho do Ator. Porto Alegre, 1996. 1 VHS.

USINA do Trabalho do Ator. Site de Divulgação. Disponível em: <www.utateatro.com>. Acesso em: 31 jan. 2012.

Eliane Tejera Lisbôa é crítica, pesquisadora, professora e diretora de teatro. É doutora em Teoria Literária pela Universidade Estadual de Campinas. Foi professora do Programa de Pós-graduação em Teatro da Universidade do Estado de Santa Catarina - UDESC e atualmente é professora de Teatro no Curso de Arte e Mídia da Universidade Federal de Campina Grande, na Paraíba. É diretora do Grupo Teatral Arupemba, em Campina Grande, Paraíba.

E-mail: elianelisboa@bol.com.br

Recebido em 25 de junho de 2012

Aprovado em 19 de agosto de 2012 